\title{
Erratum to: Program of the 105th Statistical Mechanics Conference, Rutgers University, Busch Campus, Hill Center, Room 114, Sunday, Monday, Tuesday, May 8-10, 2011
}

Joel L. Lebowitz

Published online: 4 February 2012

(C) Springer Science+Business Media, LLC 2012

Erratum to: J Stat Phys (2012) 146:663-668

DOI 10.1007/s10955-011-0387-4

The date of the next Statistical Mechanics Conference will be May 6-8, 2012.

The online version of the original article can be found under doi:10.1007/s10955-011-0387-4. 